\title{
Association between health-related physical fitness and body mass index status in children
}

Journal of Child Health Care 2016, Vol. 20(3) 294-303 (C) The Author(s) 2015 Reprints and permission: sagepub.co.uk/journalsPermissions.nav DOI: 10.1 I77//3674935/5598645 chc.sagepub.com @SAGE

\author{
Juliano Casonatto', Rômulo Araújo Fernandes², \\ Mariana Biagi Batista', Edilson Serpeloni Cyrino', \\ Manuel João Coelho-e-Silva ${ }^{3}$, Miguel de Arruda ${ }^{4}$ \\ and Enio Ricardo Vaz Ronque'
}

\begin{abstract}
The purpose of this study was to investigate the association between body mass index (BMI) status and physical performance in Brazilian children. The analyzed sample was composed of 978 children of both sexes ( 5 I 8 boys and 460 girls), aged 7 to II years. BMI and skinfolds were measured, and three motor tests were applied (flexibility, cardiorespiratory fitness, and muscular strength/ endurance). In both sexes, overweight/obese children presented poor performance in all motor tests, except flexibility. In general, overweight/obese children have an increased odds ratio (OR) to present poor physical performance (boys: $O R=3.64$ for cardiorespiratory fitness, $O R=1.94$ for muscular strength/endurance, $\mathrm{OR}=\mathrm{I} .52$ for flexibility; girls: $\mathrm{OR}=5.03$ for cardiorespiratory fitness and $O R=2.62$ for muscular strength/endurance). In conclusion, for both sexes, a poor physical performance in the tests measuring cardiorespiratory fitness and muscular strength/ endurance was associated with the presence of overweight/obesity.
\end{abstract}

\section{Keywords}

Motor tests, obesity, physical performance

\footnotetext{
I State University of Londrina, Londrina, Brazil

${ }^{2}$ Paulista State University, Presidente Prudente, Brazil

${ }^{3}$ University of Coimbra, Coimbra, Portugal

${ }^{4}$ Faculty of Physical Education, State University of Campinas, Barão Geraldo Campinas, Brazil

Corresponding author:

Mariana Biagi Batista, State University of Londrina, Rod. Celso Garcia Cid, Londrina, 860476I0, Brazil.

Email: mbiagibatista@yahoo.com.br
} 


\section{Introduction}

Obesity is characterized by excessive body fat (Flynn et al., 2006), and its development is associated with biological, genetic, and behavioral variables (Agras et al., 2004). The fast rate of increase in obesity over the last few decades has concerned health professionals (Wang and Dietz, 2002), as obesity is an important biological risk factor for the development of chronic diseases (CDs) (Falaschetti et al., 2010; Lawlor et al., 2010), associated with risk of low cardiorespiratory fitness (Artero et al., 2010; Dumith et al., 2010; Mak et al., 2010), increases the 'years of life lost', and hence public health care costs (Fontaine et al., 2003; Wang and Dietz, 2002). Thus, obesity is indicated as an important public health challenge.

Obesity and its associations with physical activity level (PAL) and lower physical fitness have been analyzed in pediatric populations (Giugliano and Carneiro, 2004; Joshi et al., 2012; Ortega et al., 2008). Prior studies have shown that both PAL and obesity track from childhood and adolescence to adulthood (Deshmukh-Taskar et al., 2006; Fernandes and Zanesco, 2010). Therefore, it is a common belief that maintenance of adequate health-related physical fitness protects against the development of CD in adulthood (Chen et al., 2002; Fernandes and Zanesco, 2010; Wedderkopp et al., 2004). Furthermore, studies have shown that obese youths are less physically active and have lower fitness than nonobese youths (Coelho-e-Silva et al., 2013; Ekelund et al., 2002; Shang et al., 2010). Thus, promoting an active lifestyle and hence adequate health-related physical fitness among children and adolescents is an important challenge to health professionals due to the harmful consequences of childhood obesity and lower fitness levels on health in adulthood.

However, in developing nations, such as Brazil, there are limited data about the existence of this association among children. Thus, the purpose of the present study was to investigate the association between body mass index (BMI) status and health-related physical fitness in Brazilian children.

\section{Methods}

\section{Sample}

This is a cross-sectional study using the database of a mixed longitudinal study entitled 'Growth Analysis and Related Fitness Physical Health in High School Level Socioeconomic' (2002-2005), and a secular trend study called 'Secular Trend in Physical Growth Indicators and Related Physical Fitness Health in School' (2010 and 2011). Thus, the information refers to the subjects assessed at a single time (cross-sectional data). All measurements were performed by trained evaluators. The data were collected in a private school located in the center of Londrina, Brazil (approximately 500,000 inhabitants), which includes approximately $15 \%$ of all children of the city.

Exclusion criteria were: (a) the child refused to participate, (b) non-parental consent, (c) some physical problem that prevented temporarily or definitively the student to be submitted to the administration of motor tests, and (d) no classes on the day of data collection. The sample of 736 children was estimated taking into account an overweight prevalence of $13.9 \%$ (Wang and Dietz, 2002), absolute error of $2.5 \%$, and a significance of $5 \%$. A total of 1068 children were measured for the study, however, after exclusions, the sample composed of 978 children (518 boys and 460 girls), with age ranging from 7 to 11 years.

Chronological age was established through the procedures indicated by Ross and Marfell-Jones (1982). Informed written consent was obtained from the participants and their parents before participating in the study, and the study protocol was approved by the ethics committee of the Londrina State University. 


\section{Anthropometry}

Weight and height were determined following the guidelines described by Gordon et al. (1988). Weight was measured, with the child standing, wearing a T-shirt and shorts without shoes, to the nearest .1 kilogram, using a precalibrated digital FILIZOLA scale that was recalibrated at each different location. Height was determined while the child was standing without shoes, to the nearest .1 centimeter, using a stadiometer. Weight and height were also used to calculate BMI, expressed as weight (kilogram) divided by height (square meter). The sex-and age-cutoffs for BMI proposed by Cole et al. (2000) were utilized to classify the BMI status. Skinfold measurements (triceps and subscapular) were taken from the right side of the body, by only one researcher, using a Lange skinfold caliper (range: 0-60 $\mathrm{mm} \times 1$ $\mathrm{mm}$; Cambridge Scientific Industries Inc., Cambridge, Massachusetts, USA) according to known procedures (Harrison et al., 1988). The median of three measurements taken in rotational form was used to represent the value for the triceps and subscapular sites. For both skinfolds, the observed intraclass correlation (reliability) was .95 and the standard error was less than $\pm 1.0 \mathrm{~mm}$.

\section{Health-related physical fitness}

Health-related physical fitness was assessed through three motor tests. The participants performed a 'sit-and-reach' test (flexibility), followed by 'sit-ups' (muscular strength and endurance), and a 'nine-minute run/walk' test (cardiorespiratory fitness). The sit-and-reach test was performed by the participants according to known procedures (American Alliance for Health, Physical Education, Recreation and Dance, 1984). The participants were each given three trials, and the best value was used as the test score. All participants received verbal encouragement from the investigators in order to achieve maximum performance. In each test, the sex-and-age specific cutoffs of Physical Best proposed by the American Alliance for Health Physical, Education, Recreation, and Dance (1984) were adopted to indicate satisfactory or unsatisfactory performance.

\section{Statistical analyses}

The data were stored and analyzed using the Statistical Package for Social Sciences (SPSS for Windows Version 17.0). Normality was checked and rejected using the Kolmogorov-Smirnov test. Thus, median values and interquartile range were adopted as descriptive statistics. The MannWhitney $U$ test was used when comparing differences in physical characteristics between sexes, while the Kruskal-Wallis test was used to analyze indicators of the health-related physical fitness in relation to BMI status stratified in boys and girls. The association between nutritional status and physical performance was assessed by the $\chi^{2}$ test, and the magnitude of this association was expressed by multiple logistic regression (odds ratio (OR) and $95 \%$ confidence interval (95\% CI)), which was adjusted by chronological age. The statistical significance was set at $p<.05$.

\section{Results}

The physical characteristics of the sample are shown in Table 1. For both sexes, there were no statistical differences in the variables: age $(p=.896)$, weight $(p=.123)$, or height $(p=.470)$. However, boys presented higher values of BMI than girls $(p=.039)$. The prevalence of overweight was around $20 \%$ for boys and girls, and obesity was $10 \%$ for boys and $6 \%$ for girls.

Table 2 presents the scores of the health-related physical fitness according to the BMI status. In general, for both sexes, obese children presented higher subcutaneous fat and lower muscle 
Table I. Physical characteristics of Brazilian children aged 7-II years by sex. ${ }^{a}$

\begin{tabular}{lccc}
\hline Variables & $\begin{array}{c}\text { Boys }(n=5 \mid 8) \\
\text { Median }(\mathrm{IR})\end{array}$ & $\begin{array}{c}\text { Girls }(n=460) \\
\text { Median }(\mathrm{IR})\end{array}$ & Mann-Whitney p value \\
\hline Age $($ years) & $8.5(2.2)$ & $8.6(2.4)$ & .896 \\
Weight $(\mathrm{kg})$ & $30.7(12.3)$ & $29.8(11.4)$ & .123 \\
Height $(\mathrm{cm})$ & $133.0(13.4)$ & $132.0(14.1)$ & .470 \\
BMI $\left(\mathrm{kg} / \mathrm{m}^{2}\right)$ & $17.3(4.1)$ & $17.1(3.6)$ & .039 \\
BMI Status $(n(\%))$ & & & $.092^{\mathrm{b}}$ \\
Healthy weight & $367(70.8)$ & $340(73.9)$ & \\
Overweight & $99(19.1)$ & $91(19.8)$ & \\
Obesity & $52(10.0)$ & $29(6.3)$ & \\
\hline
\end{tabular}

Note: BMI: body mass index; IR: interquartile range.

${ }^{a}$ Values are reported as median (interquartile range).

${ }^{b} \chi^{2}$ test for linear trend.

Table 2. Indicators of the health-related physical fitness in Brazilian children aged 7-I I years by sex and BMI status. $^{\text {a }}$

\begin{tabular}{|c|c|c|c|c|}
\hline & $\begin{array}{l}\text { Healthy BMI } \\
\text { Median (IR) }\end{array}$ & $\begin{array}{l}\text { Overweight } \\
\text { Median (IR) }\end{array}$ & $\begin{array}{c}\text { Obesity } \\
\text { Median (IR) }\end{array}$ & $\begin{array}{c}\text { Kruskal-Wallis } \\
P \text { value }\end{array}$ \\
\hline Boys $(n=518)$ & $(n=367)$ & $(n=99)$ & $(n=52)$ & \\
\hline Age (years) & $8.3(2.2)$ & $8.9(1.9)^{*}$ & $8.6(1.7)$ & .001 \\
\hline$\sum \mathrm{SF}(\mathrm{mm})$ & I7.0 (6.5) & $32.0(11.5)^{*}$ & $42.7(14.1)^{* \dagger}$ & .001 \\
\hline SRT $(\mathrm{cm})$ & $27.0(8.0)$ & $25.0(7.0)$ & $24.5(9.0)$ & .087 \\
\hline SUT (rep) & $32.0(10.0)$ & $31.0(11.0)$ & $25.5(12.0)^{* \dagger}$ & .001 \\
\hline $\mathrm{CFT}(\mathrm{m})$ & I $350.0(302.0)$ & I $265.0(275.0)^{*}$ & $1115.0(190.0)^{* \dagger}$ & .001 \\
\hline Girls $(n=460)$ & $(n=340)$ & $(n=91)$ & $(n=29)$ & \\
\hline Age (years) & $8.7(2.4)$ & $8.2(2.4)$ & $8.1(2.4)$ & .642 \\
\hline$\sum \mathrm{SF}(\mathrm{mm})$ & $20.5(9.5)$ & $33.0(13)^{*}$ & $45.0(15)^{* \dagger}$ & .001 \\
\hline SRT $(\mathrm{cm})$ & $29.0(8.0)$ & $29(10)$ & $27(8)$ & .587 \\
\hline SUT (rep) & $31.0(11.0)$ & $27(10)^{*}$ & $23(13)^{* \dagger}$ & .001 \\
\hline $\mathrm{CFT}(\mathrm{m})$ & $1215.0(239.0)$ & II 130 (140)* & $1075(220)^{* \dagger}$ & .001 \\
\hline
\end{tabular}

Note: IR: interquartile range; $\Sigma$ SF: sum of triceps and subscapular skinfolds; SRT: sit-and-reach test; SUT: sit-ups test; CFT: cardiorespiratory fitness test; BMI: body mass index. Values are reported as median (interquartile range).

${ }^{a}$ Levels of significance for the BMI status differences based on the Kruskal-Wallis test.

${ }^{*} p<.05$ versus healthy BMI; ${ }^{\dagger} p<.05$ versus overweight.

strength and endurance than those of healthy weight. However, in boys $(p=.087)$ and girls $(p=$ .587 ), there were no differences for flexibility, according to the BMI status.

Unsatisfactory performance in the flexibility test was higher in overweight/obese boys ( $p=$ .035 (Figure 1, (a)), but this pattern was not identified in girls $(p=.200$ (Figure 1, (b))). Independent of sex, decreased performance in muscle strength was higher in overweight/obese children ( $p=.001$ for both). Boys presented lower rates of unsatisfactory performance in muscle endurance; on the other hand, in both boys and girls, BMI was strongly associated with lower performance in the running test ( $p=.001$ for both). 


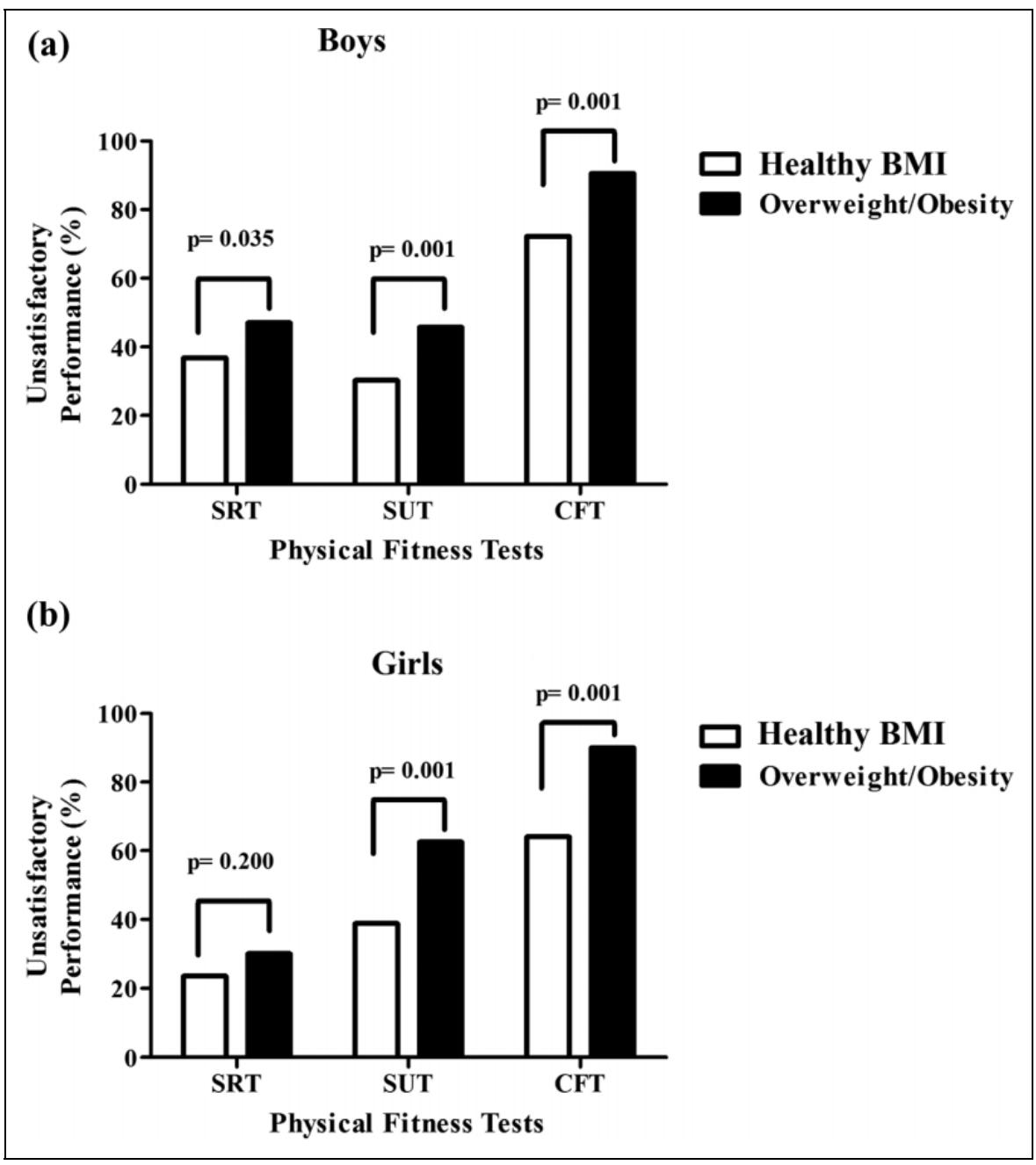

Figure I. Association between health-related physical fitness and nutritional status in Brazilian boys (a) and girls (b) children aged 7-II years. SRT: sit-and-reach test; SUT: sit-ups test; CFT: cardiorespiratory fitness test; BMI: body mass index.

Children considered overweight/obese were significantly more likely to demonstrate low health-related physical fitness (cardiorespiratory fitness: OR $=3.6$ for boys and 5.0 for girls, muscular strength/endurance: $\mathrm{OR}=1.9$ and 2.6 for boys and girls, respectively; flexibility: $\mathrm{OR}=$ 1.5 only for boys), compared to their peers with healthy BMI (Figure 2(a) and (b)).

\section{Discussion}

This was a cross-sectional study, in which a large sample of children and adolescents was analyzed and a strong association was identified between overweight and lower performance in healthrelated physical fitness. 
(a)

\section{Boys}

\section{Unsatisfactory Performance}

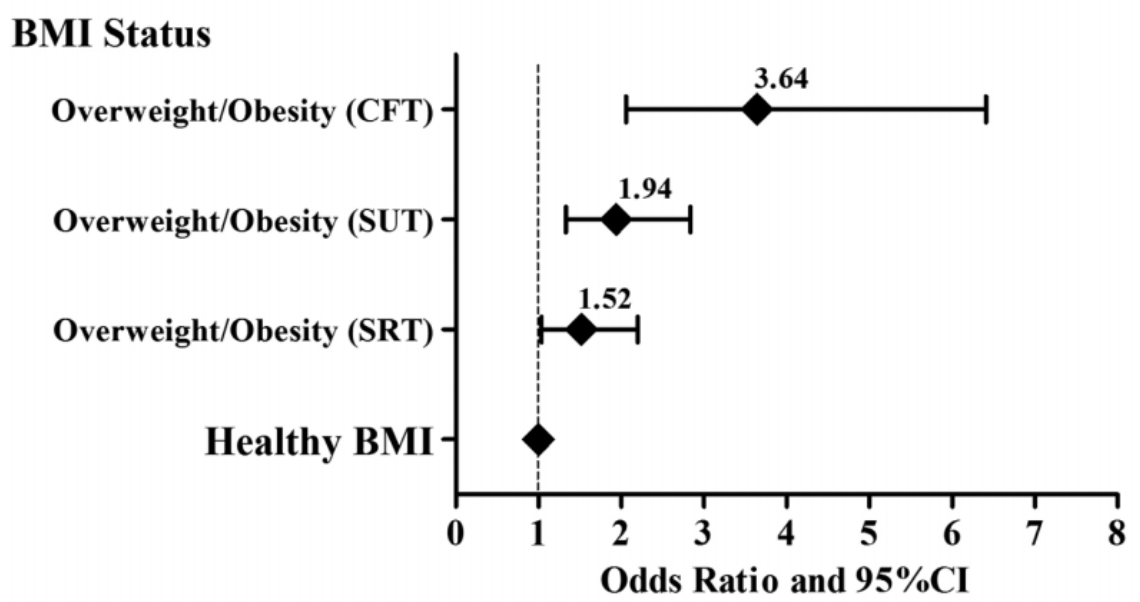

(b)

Girls

Unsatisfactory Performance

BMI Status

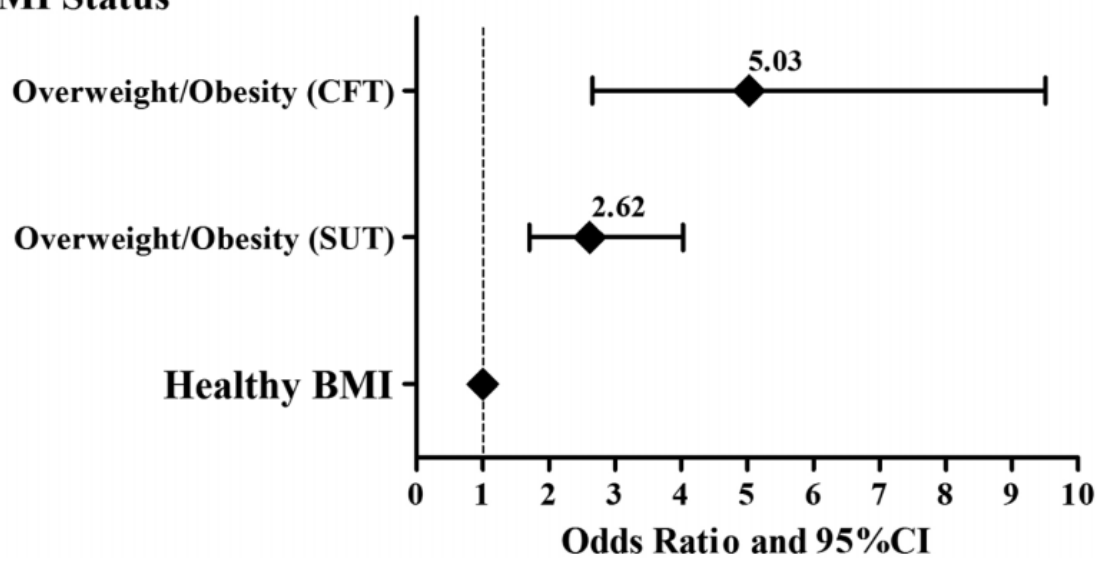

Figure 2. Logistic regression for association between BMI status and health-related physical fitness in Brazilian boys (a) and girls (b) children aged 7-I I years. SRT: sit-and-reach test; SUT: sit-ups test; CFT: cardiorespiratory fitness test; BMI: body mass index.

Recent evidence has reinforced the beneficial effects of promoting a physically active lifestyle from childhood (Moreira et al., 2011). It is well documented that PAL tracks from childhood to adulthood and if initiated at an early age is associated with a lower occurrence of obesity and CDs in adulthood, such as arterial hypertension and type 2 diabetes mellitus (Fernandes and 
Zanesco, 2010). Corroborating with the harmful effects of pediatric obesity and ratifying the necessity for its prevention through physical activity practice, BMI values at seven-year-old are strongly related to values of blood pressure, blood glucose, and cholesterol presented in young adulthood (Sinaiko et al., 1999).

In our study, overweight/obese children presented decreased muscle strength and cardiorespiratory fitness, a harmful effect that was observed independent of sex. Prior studies have reported that obese children present poor performances in all indicators of health-related physical fitness, except flexibility (Artero et al., 2010; Kim et al., 2005; Tokmakidis et al., 2006). Among pediatric populations, health-related physical fitness is an important indicator of physical health (Chen et al., 2002; Ortega et al., 2008), and its relationship with obesity is an unhealthy effect previously documented only in developed nations. The poor performances of overweight children cannot be attributed exclusively to the increased difficulty of body locomotion and muscular injuries caused by the excessive weight (Wearing et al., 2006). In fact, the above-mentioned relationship could be affected by confounders such as PAL because in adolescents there is an inverse relationship between physical activity and body fat as well as a positive relationship between physical activity and cardiorespiratory fitness (Gutin et al., 2005).

In this regard, Stodden et al. (2008) presented a model that seeks to explain the relationship between obesity, physical activity, and physical fitness, focused on the acquisition and development of motor skills. This model considers a dynamic and reciprocal relationship between obesity and four other factors (physical activity, motor skill competence, perceived motor competence, and physical fitness).

If on one hand, there is a positive spiral of involvement and perception of high competence of motor skills, greater physical activity and higher levels of physical fitness and health, promoting a state of healthy weight; on the other, the negative spiral points to a cessation of physical activity with low competence and perception of motor skills, less physical activity, and poor physical fitness and health, leading to weight gain and obesity. Therefore, the relationship between obesity and physical fitness is characterized as highly complex since the variables involved can compromise these interpretations (Stodden et al., 2008).

In fact, in the present study, more than $90 \%$ and $40 \%$ of the obese children presented unsatisfactory performances in cardiorespiratory fitness and muscular strength/endurance, respectively. However, in both sexes, nonobese children also presented high rates of unsatisfactory performance, higher rates than those observed in previous studies (Dumith et al., 2010; Huang and Malina, 2002).

It is worth mentioning that, in the case of flexibility evaluated by the sit-and-reach test, performance was not affected by overweight/obesity in either sex, a result that has also been observed in other studies (Malina et al., 1995; Tokmakidis et al., 2006). One possible explanation for this behavior lies in the fact that physical activities involving flexibility, unlike those of endurance, agility, and explosive power, are not significantly affected by overweight and are thus equally attractive to both eutrophic and overweight children and adolescents (Fogelholm et al., 2008).

Another consideration is that the test used as an indicator of flexibility (sit-and-reach), used internationally for epidemiological studies, has some limitations such as the fact that it verifies the flexibility of the hip region and this is dependent on leg length proportions (sitting height), added to which, there is little evidence of the validity of this test in this population (Castro-Piñero et al., 2010).

Our results suggest a possible influence of overweight/obesity on the physical health of children; however, due to the cross-sectional design it is not possible to establish a causal relationship, 
that is, inadequate physical fitness may cause obesity or obesity may lead to low physical fitness. Thus, further longitudinal studies are necessary to fill this gap in the literature. Additionally, the fact that only a private school was selected to participate in the study is presented as a potential limitation since such results cannot be extrapolated to young people studying in public schools in the same municipality.

\section{Conclusion}

In summary, our data analyzed the relationship between BMI status and health-related physical fitness in a large sample of children and indicated that there was a significant association between overweight and lower performance in indicators of health-related physical fitness in our sample.

The results suggest that children are encouraged to increase their participation in physical education classes and institutions such as clubs, association communities that may provide extracurricular activities, such as physical exercise programs, sports organized, and recreational activities to this population, seeking appropriate levels of physical fitness related to health. In this sense, government actions should be developed to deal with the effects related to the increase of overweight in children, otherwise in the future, the impact on public spending as a result of CDs would be a major public health problem in Brazil.

\section{Acknowledgments}

The authors thank all the participants who engaged in this study and also the Coordination for the Improvement of Higher Education Personnel (CAPES, Brazil) by the scholarship (Mariana Biagi Batista) and the National Council of Scientific and Technological Development (CNPq, Brazil) for productive research grant (Enio Ricardo Vaz Ronque and Edilson Serpeloni Cyrino).

\section{Conflict of interest}

The author(s) declared no potential conflicts of interest with respect to the research, authorship, and/or publication of this article.

\section{Funding}

The author(s) received no financial support for the research, authorship, and/or publication of this article.

\section{References}

Agras WS, Hammer LD, McNicholas F, et al. (2004) Risk factors for childhood overweight: a prospective study from birth to 9.5 years. The Journal of Pediatrics 145(1): 20-25.

American Alliance for Health, Physical Education, Recreation and Dance (1984) Technical Manual: Health Related Physical Fitness. Reston: The American Alliance for Health, Physical Education, Recreation and Dance.

Artero EG, España-Romero V, Ortega FB, et al. (2010) Health-related fitness in adolescents: underweight, and not only overweight, as an influencing factor. The AVENA study. Scandinavian Journal of Medicine \& Science in Sports 20(3): 418-427.

Castro-Piñero J, Artero EG, España-Romero V, et al. (2010) Criterion-related validity of field based fitness tests in youth: a systematic review. British Journal of Sports Medicine 44(13): 934-943.

Chen W, Lin CC, Peng CT, et al. (2002) Approaching healthy body mass index norms for children and adolescents from health-related physical fitness. Obesity Reviews 3(3): 225-232. 
Coelho-e-Silva MJ, Ronque ERV, Cyrino ES, et al (2013) Nutritional status, biological maturation and cardiorespiratory fitness in Azorean youth aged 11-15 years. BMC Public Health 13(495): 1-10.

Cole TJ, Bellizzi MC, Flegal KM, et al. (2000) Establishing a standard definition for child overweight and obesity worldwide: international survey. British Medical Journal 320(6): 1240-1243.

Deshmukh-Taskar P, Nicklas TA and Morales M (2006) Tracking of overweight status from childhood to young adulthood: the Bogalusa heart study. European Journal of Clinical Nutrition 60(1): 48-57.

Dumith SC, Ramires VV, Souza MA, et al. (2010) Overweight/obesity and physical fitness among children and adolescents. Journal of Physical Activity Health 7(5): 641-648.

Ekelund U, Aman J, Yngve A, et al. (2002) Physical activity but not energy expenditure is reduced in obese adolescents: a case-control study. American Journal of Clinical Nutrition 76 (5): 935-941.

Falaschetti E, Hingorani AD, Jones A, et al. (2010) Adiposity and cardiovascular risk factors in a large contemporary population of pre-pubertal children. European Heart Journal 31(24): 3063-3072.

Fernandes RA and Zanesco A (2010) Early physical activity promotes lower prevalence of chronic diseases in adults. Hypertension Research 33(9): 926-931.

Flynn MA, McNeil DA, Maloff B, et al. (2006) Reducing obesity and related chronic disease risk in children and youth: a synthesis of evidence with 'best practice' recommendations. Obesity Reviews 7(Suppl 1): $7-66$.

Fogelholm M, Stigman S and Huisman T (2008) Physical fitness in adolescents with normal weight and overweight. Scandinavian Journal of Medicine \& Science in Sports 18(2): 162-170.

Fontaine KR, Redden DT, Wang C, et al. (2003) Years of life lost due to obesity. Journal of the American Medical Association 289(2): 187-193.

Giugliano R and Carneiro EC (2004) Factors associated with obesity in school children. Jornal de Pediatria 80(1): 17-22.

Gordon CC, Chumlea WC and Roche AF (1988) Stature, recumbent length, and weight. In: Lohman TG, Roche AF and Martorell R (eds) Anthropometric standardization reference manual. Champaign: Human Kinetics Books, pp. 3-8.

Gutin B, Yin Z, Humphries MC, et al. (2005) Relations of moderate and vigorous physical activity to fitness and fatness in adolescents. American Journal of Clinical Nutrition 81(4): 746-750.

Harrison G, Buskirk E, Carter L, et al. (1988) Skinfold thicknesses and measurement technique. In: Lohman T, Roche A and Martorell R (eds) Anthropometric standardization reference manual. Champaign: Human Kinetics Books, pp. 55-70.

Huang YC and Malina RM (2002) Physical activity and health-related physical fitness in Taiwanese adolescents. Journal of Physiological Anthropology and Applied Human Science 21(1): 11-19.

Joshi P, Bryan C and Howa H (2012) Relationship of body mass index and fitness levels among schoolchildren. Journal of Strength and Conditioning Research 26(4): 1006-1014.

Kim J, Must A, Fitzmaurice GM, et al. (2005) Relationship of physical fitness to prevalence and incidence of overweight among schoolchildren. Obesity Research 13(7): 1246-1254.

Lawlor DA, Benfield L, Logue J, et al. (2010) Association between general and central adiposity in childhood, and change in these, with cardiovascular risk factors in adolescence: prospective cohort study. British Medical Journal 25(341): 1-11.

Mak KK, Ho SY, Lo WS, et al. (2010) Health-related physical fitness and weight status in Hong Kong adolescents. BMC Public Health 10(88): 1-5.

Malina RM, Beunen GP, Classens AL, et al. (1995) Fatness and physical fitness of girls 7 to 17 years. Obesity Research 3(3): 221-231.

Moreira C, Santos R, Farias Junior JC, et al. (2011) Metabolic risk factors, physical activity and physical fitness in Azorean adolescents: a cross-sectional study. BMC Public Health 11(214): 1-7. 
Ortega FB, Ruiz JR, Castillo MJ, et al. (2008) Physical fitness in childhood and adolescence: a powerful marker of health. International Journal of Obesity 32(1): 1-11.

Ross WD and Marfell-Jones MJ (1982) Kinanthropometry. In: MacDougall JD, Wenger HA and Green HJ (eds) Physiological Testing of the Elite Athlete. Ottawa: Mutual, pp. 75-115.

Shang X, Liu A, Li Y, et al. (2010). The association of weight status with physical fitness among Chinese children. International Journal of Pediatrics (1): 1-6.

Sinaiko AR, Donahue RP, Jacobs DR, et al. (1999). Relation of weight and rate of increase in weight during childhood and adolescence to body size, blood pressure, fasting insulin, and lipids in young adults. The Minneapolis Childrens Blood Pressure Study. Circulation 99(11): 1471-1476.

Stodden DF, Goodway JD, Langendorfer SJ, et al. (2008). A developmental perspective on the role of motor skill competence in physical activity: an emergent relationship. Quest 60(1): 290-306.

Tokmakidis SP, Kasambalis A and Christodoulos AD (2006) Fitness levels of Greek primary school children in relationship to overweight and obesity. European Journal of Pediatrics 165(12): 867-874.

Wang G and Dietz WH (2002) Economic burden of obesity in youths aged 6 to 17 years: 1979-1999. Pediatrics 109(5): E81-E81.

Wearing SC, Hennig EM, Byrne NM, et al. (2006) The impact of childhood obesity on musculoskeletal form. Obesity Reviews 7(2): 209-218.

Wedderkopp N, Froberg K, Hansen HS, et al (2004) Secular trends in physical fitness and obesity in Danish 9year-old girls and boys: Odense School Child Study and Danish substudy of the European Youth Heart Study. Scandinavian Journal of Medicine \& Science in Sports 14(3): 150-155. 